\title{
Method Study on Information Safety Capability Evaluation of Internet Finance Enterprise
}

\author{
Dongsheng Yu \\ The Third Research Institute of Ministry of Public Security, Beijing, China \\ Yu.dongsheng@cspec.org.cn
}

Keywords: Internet finance, information safety capability, evaluation.

\begin{abstract}
Information safety capability evaluation of Internet finance enterprise is an important foundation work boosting Internet finance to develop in a safe, healthy and orderly way, however, presently there has not been any feasible method to assess Internet finance enterprise information safety capability. Starting from internet finance enterprise information safety goal, referencing domestic and overseas information safety standards, and considering the industry features of Internet finance, this paper designs a set of Internet finance enterprise safety capability evaluation methods, which serves as reference for carrying out Internet finance enterprise information safety capability evaluation in the future.
\end{abstract}

\section{Introduction}

With the speedy development and extensive use of internet technology greatly influencing all walks of life in the society, financial business carried out through internet develops rapidly and comes in many modes such as third-party payment, P2P internet loan, large data finance and crowd funding. Meanwhile, due to the immature network safety protecting mechanism in the country, the weak awareness of internet finance participants on data safety and customer information safety risk prevention, and information safety of internet finance enterprise faces serious challenge.

Analyzing safety risks faced by internet finance enterprise, referencing domestic and overseas technical standard specifications such as GB/T20261-2006 Information Technology System Safety Capability Maturity Model, YD/T 3169-2016 Internet New Technology \& Business Safety Evaluation Specification, ISO/IEC 27001:2013 Information Technology Safety Technology Information Safety Management System Requirement, and considering the feature of internet finance industry, this text designs a set of internet finance enterprise information safety capability evaluation methods including safety capability evaluation model, evaluation index and evaluation method.

\section{Information Safety Capability Evaluation Model}

In order to ensure that internet finance enterprise information safety construction is boosted orderly and ultimately realize safety goal, a set of reasonable evaluation models and methods is needed to effectively examine and evaluate safety construction effect; this set of models and methods should adapt to complex construction actuality and include methods, models and processes to quantify evaluation.

Currently, in domestic information safety capability maturity model aspect, our country has published GB/T20261-2006 Information Technology System Safety Project Capability Maturity Model, which basically defines safety project capability maturity evaluation and defines five levels of safety capability as informal execution level, planning and tracking level, appropriate definition level, quantitative level and continual improvement level; these five levels of safety capability sufficiently define capability feature and describe 11 system safety project process domains and fundamental conventions. Through referencing the above models and relevant standards, on the basis of the best practice of internet finance industry safety capability evaluation, starting from 
quantification of evaluation index, information safety capability dimensionality and information safety domain, and surrounding five-level capability maturity model, a set of internet finance enterprise information safety capability evaluation models is formed, as shown below:

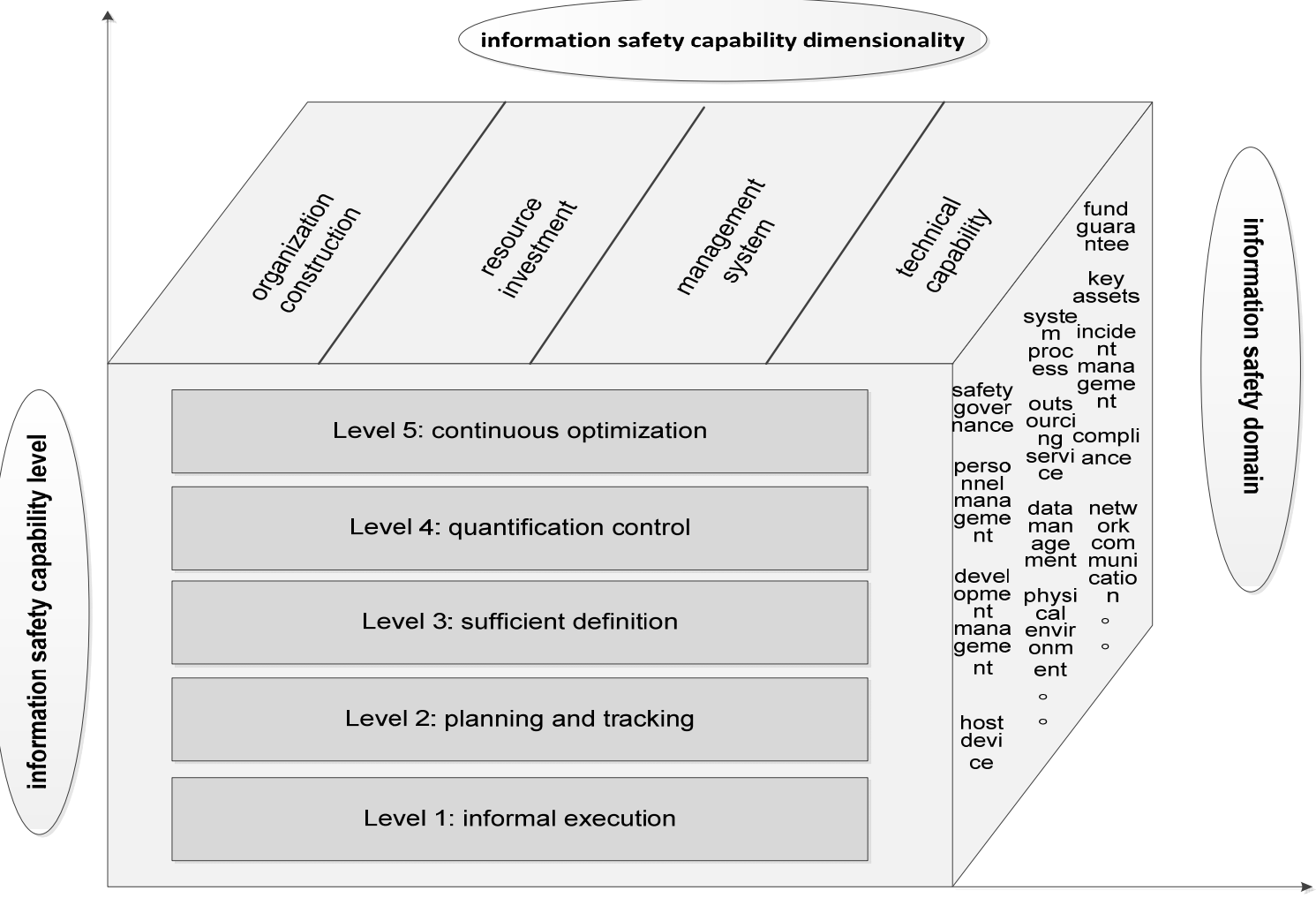

Fig.1. Internet Finance Enterprise Information Safety Capability Evaluation Model

Safety capability evaluation model is composed of the following three aspects: 1 . Information safety domain: centering on enterprise and information safety related field, the model includes 17 safety domains, namely, information safety governance, safety organization system, safety system process, safety fund assurance, business compliance, business risk control, personnel safety management, key information asset management, outsourcing service management, emergency and incident management, network communication safety, host and equipment safety, application system safety, data management safety, developing management safety, physical environment safety and terminal management safety; 2 . Information safety capability dimensionality: the model classifies the capability an enterprise need possess in information safety field into four dimensionalities, namely, organization construction, resource investment, management system and technical capability; 3. Information safety capability level: the model defines five levels of capability maturity, refining enterprise grading requirement on entire information safety capability maturity based on unified grading standard.

\section{Information Safety Capability Evaluation Index}

Using grading and layering method, this evaluation index design carries out classification according to degrees of influences of all factor characteristics of internet finance enterprise safety capability evaluation index on the entire information safety evaluation system and forms a tree-like hierarchical structure. The first layer of tree-like structure decides the key elements of evaluation object, the following layers decompose and detail the key elements respectively, in the end, a set of detailed evaluation index used for evaluation marking is formed; information safety capability evaluation index system mainly includes four dimensionalities of organization construction, resource investment, management system and technical capability, 17 safety domains and 373 items of evaluation index, as shown in Figure 2: 


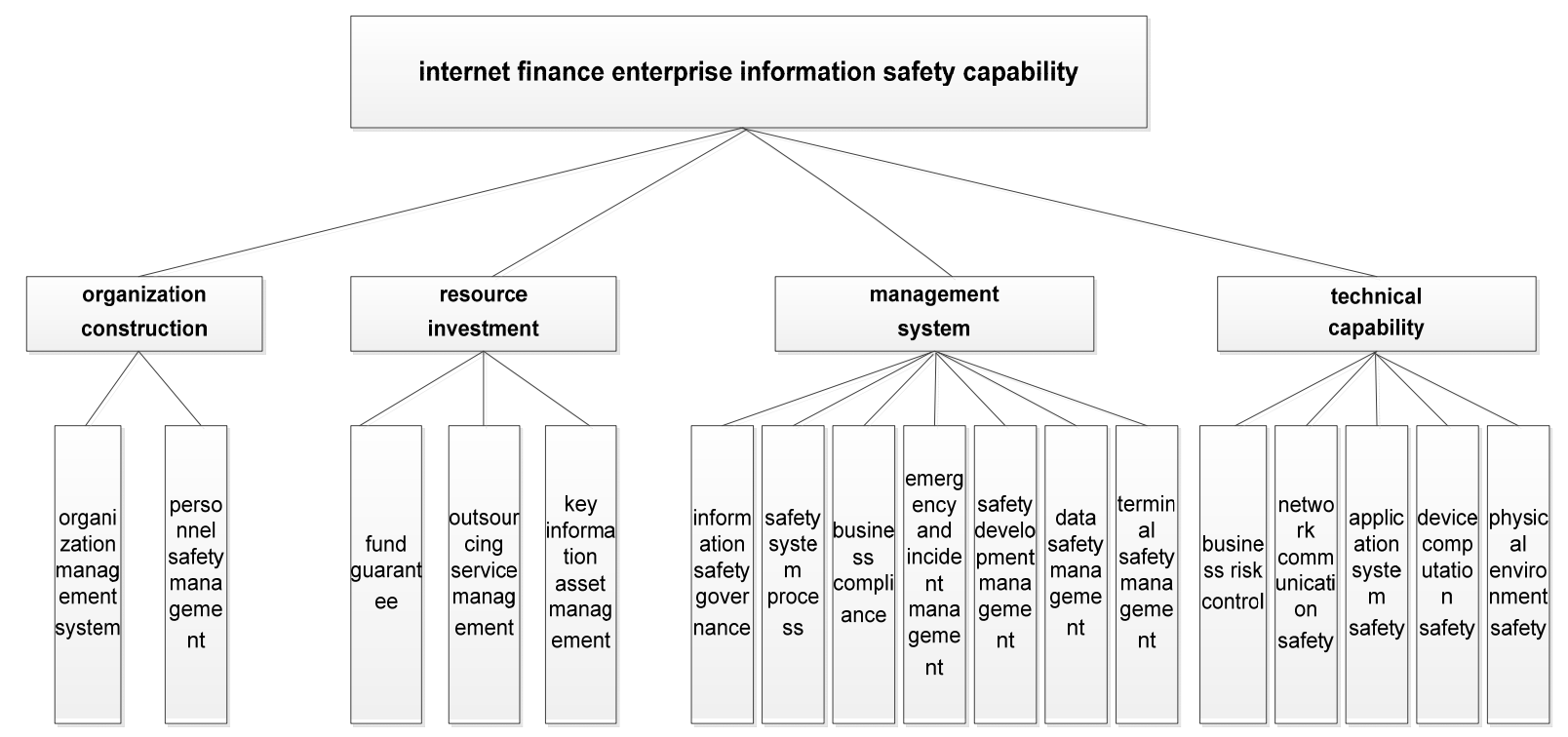

Fig. 2. Information Safety Capability Evaluation Index System

TABLE.1. Information Safety Capability Evaluation Index

\begin{tabular}{|c|c|c|c|c|c|}
\hline $\begin{array}{c}\text { Safety } \\
\text { Domain }\end{array}$ & $\begin{array}{l}\text { Level } 1 \text { of } \\
\text { Index }\end{array}$ & $\begin{array}{l}\text { Level } 2 \text { of } \\
\text { Index }\end{array}$ & & evel 3 of Index & Inspection Method \\
\hline \multirow{3}{*}{$\begin{array}{c}\text { Informatio } \\
\text { n Safety } \\
\text { Governance } \\
\text { (ISM) }\end{array}$} & \multirow{3}{*}{$\begin{array}{l}\text { Information } \\
\text { Safety } \\
\text { Governance }\end{array}$} & $\begin{array}{l}\text { Information } \\
\text { safety } \\
\text { positioning }\end{array}$ & $\begin{array}{c}\text { ISM } \\
1\end{array}$ & $\begin{array}{l}\text { a) Enterprise } \\
\text { management should } \\
\text { position information } \\
\text { safety as one of core } \\
\text { competing forces of } \\
\text { enterprise } \\
\text { development. }\end{array}$ & $\begin{array}{l}\text { 1) Interviewing enterprise management } \\
\text { information safety competent leader and } \\
\text { information safety director, inquiring } \\
\text { about information safety positioning in } \\
\text { enterprise; } \\
\text { 2)Consulting documents, consulting } \\
\text { enterprise information safety governance } \\
\text { strategy documents. }\end{array}$ \\
\hline & & $\begin{array}{l}\text { Information } \\
\text { safety } \\
\text { outlook }\end{array}$ & $\begin{array}{c}\text { ISM } \\
2\end{array}$ & $\begin{array}{l}\text { a) Enterprise } \\
\text { management and all } \\
\text { the staff should set } \\
\text { up correct enterprise } \\
\text { information safety } \\
\text { outlook. }\end{array}$ & $\begin{array}{l}\text { 1) Interviewing enterprise management } \\
\text { information safety competent leader and } \\
\text { information safety director, inquiring } \\
\text { about enterprise information safety } \\
\text { governance idea and viewpoint; } \\
\text { 2)Consulting documents, consulting } \\
\text { enterprise information safety governance } \\
\text { meeting minutes. }\end{array}$ \\
\hline & & $\begin{array}{l}\text { Information } \\
\text { safety } \\
\text { development } \\
\text { direction }\end{array}$ & $\begin{array}{c}\text { ISM } \\
\mathbf{3}\end{array}$ & ....... & $\cdots \cdots$. \\
\hline
\end{tabular}

Organization construction mainly inspects whether there exist reasonable organization management system architecture and complete personnel management in information safety assurance work, with the evaluation index mainly including information safety organization architecture, first responsible person establishment, information safety responsibility implementation, full-time institution and post setting, safety staffing and industry safety supervision.

Resource investment mainly inspects whether internet finance enterprise has input sufficient resources in information safety assurance work; considering fund guarantee, outsourcing service and key asset management, its evaluation index mainly includes safety development planning, expenditure budget, safety construction expenditure input, safety operation and maintenance expenditure input, supplier relation information safety strategy, supplier service supervision and appraisal, supplier service changing management and outsourcing operation and maintenance management. 
As an important dimensionality assessing internet finance enterprise information safety capability, management system mainly inspects whether information safety management system is full and complete, whether safety work is fulfilled, and whether effective risk management is carried out, mainly including information safety governance, safety system process, emergency and incident management, safety development management, data safety management, terminal safety management and business compliance.

Technical capability is also an emphasis in evaluation system; it mainly inspects internet finance enterprise information safety technology assurance capability and business risk control capability, mainly including network communication safety, application system safety, device computation safety, physical environment safety and business risk control.

Through decomposing index layer by layer, one to three levels of index under each safety domain are designed, and inspection methods corresponding to three levels of index are designed, as shown in Table 1.

\section{Information Safety Capability Evaluation Method}

After information safety evaluation index is determined, it's necessary to design evaluation method, with the main contents including index marking method, weighing design and marking principle, and result calculation and analysis.

\subsection{Index Marking Method.}

Index marking method is to carry out marking based on whether internet finance enterprise information safety work actuality conforms to the inspection items. Assigning each inspection item weighing value (Vij), giving quantified value (Pij) according to inspection result judgment, we come at safety inspection result quantification through calculation using Formula (1):

$$
\mathrm{ISL}=\sum_{i=1}^{\mathrm{n}}\left(\sum_{j=1}^{m} V_{i j} P_{i j}\right)
$$

Where:

$\mathrm{n}-$ inspection item number

$\mathrm{m}-$ number of inspection clauses in Inspection Item $\mathrm{i}$

\subsection{Weighing Design and Marking.}

Index weighing means setting different quantification grades according to degrees of influences of evaluation index items on enterprise information safety capability level or degrees of risks resulting from evaluation index incompliance. Index weighing values take integers from 1 to 5, with the smallest value being 1 and biggest value being 5 .

The single scores for evaluation index in evaluation system take value between 0 and 1 , with the lowest scores being 0 and full scores being 1; the marking principle is shown below:

We assign evaluation index quantified value based on whether information safety work actuality conforms to index evaluation requirement, with the assigning method being listed in Table 4. For the index item which completely meets evaluation index requirement, the scores are 1; for the index item which doesn't follow evaluation index requirement, the scores are 0 ; for the index item which fails to completely meet evaluation index requirement, the scores are determined according to ratio method.

TABLE.2. Assigning Method Based on conformity/inconformity Judgment

\begin{tabular}{|c|c|}
\hline Information Safety Work Actuality to Evaluation Index Requirement & Scores \\
\hline not following evaluation index requirement at all & 0 \\
\hline partly meeting evaluation index requirement & 0.5 \\
\hline completely meeting evaluation index requirement & 1 \\
\hline
\end{tabular}




\subsection{Result Calculation and Analysis.}

After understanding evaluation index items and their weighing, we choose appropriate analysis method to get quantified data result and provide basis for enterprise carrying out information safety capacity analysis. Result calculation and analysis method is as follows:

Scores of Level 3 index items after weighing. After understanding weighing combination of Level 3 index items, experts or evaluators carry out marking on enterprise Level 3 index items and then obtain their scores after weighing, using the following formula:

$$
c_{i}=c_{j} \times W_{l}
$$

Where, represents scores or ratio scores of each Level 3 index, $w_{i}$ represents weighing value of each Level 3 index.

Scores of each upper level index item. We obtain scores of each upper level index item by summing scores of Level 3 index items of each dimensionality or domain after weighing, using the following formula:

$$
Y_{t}=\sum_{t=1}^{v i} C_{t}
$$

Where, m represents number of Level 3 index items of each dimensionality or domain, represents scores of each Level 3 index item after weighing.

Total scores of enterprise information safety capability level. We obtain total scores of enterprise information safety capability level by summing scores of upper level index items, using the following formula:

$$
Y=\sum_{t=1}^{t} y_{l}
$$

Where, $t$ represents number of dimensionalities or domains the system has, represents scores of each index dimensionality or domain.

Result analysis: the scores in this step are quantified value of enterprise information safety capability level; the higher the scores are, the stronger enterprise information safety capability is.

Satisfaction of index items of each dimensionality or domain. The percentage of scores of index items of each dimensionality or domain to the full scores is used to represent satisfaction of index items of each dimensionality or domain, with the formula being:

$$
Q=\frac{\gamma_{l}}{D_{l}}
$$

Where, $Y_{i}$ represents scores of dimensionality or domain, represents the full scores of dimensionality or domain, i.e. $D_{l}=1 \times \mathrm{w}$ elgh/ng of index items of each dimensionality or domain.

Result analysis: the percentage gotten in this step represents the extent to which index items of each dimensionality or domain are realized in information safety activity.

\section{Summary}

Referencing domestic and overseas information safety standards and considering the industry features of internet finance, this text designs a set of internet finance enterprise information safety capability evaluation models and operable evaluation methods, by means of which safety evaluation institution or internet finance enterprise can carry out evaluation on internet finance enterprise information safety capability so as to lay a foundation for further enhancing internet finance enterprise safety capability; meanwhile, these safety capability evaluation models and methods can also serve as reference for other industries carrying out safety capability evaluation. 


\section{References}

[1] XIE Erman, Huang Xu, Zhou yang. "Analysis of network security and information security elements of Internet finance"[J]. Journal of Shanghai University (Social Sciences) 2015(32), pp. 27-35.

[2] YAO Guozhang, ZHAO Gang. "Internet finance and risk control”[J].

Journal of Nanjing University of Posts and Telecommunications (Natural Science Edition) 2015(35), pp. 8-20.

[3] Zhang Yunlong, Hua Yong. "Using PCA to Evaluate Computer Network Security"[J]. National Conference on Information Technology and Computer Science (CITCS 2012).

[4] Yuan Xiaoke. "Research of information system security evaluation model based on A-Delphi method"[J]. Microcomputers and ITS applications 2012 (31), pp. 54-57.

[5] WANG Chundong, ZHANG Yu. "Network Security Situation Evaluation Based on Modified D-S Evidence Theory“[J].Wuhan University Journal of Natural Sciences.2014 (19). 